\title{
The effect of infertility on mental health in infertile women and men
}

Borbála Eszter Hegyi, MD

Ph.D. Thesis

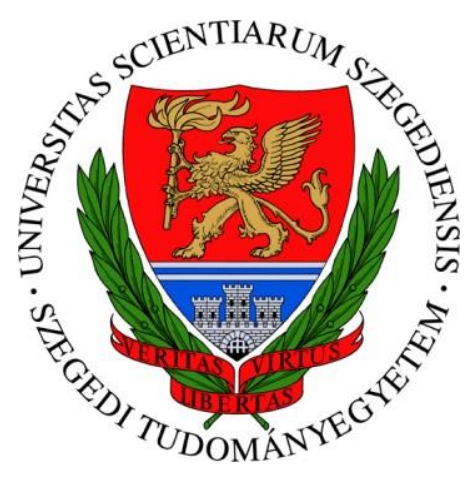

Department of Obstetrics and Gynecology

\author{
Albert Szent-Györgyi Clinical Center \\ Doctoral School of Clinical Medicine \\ University of Szeged
}

Supervisor: Norbert Pásztor M.D., Ph.D.

Szeged

2020 


\section{Table of Contents}

Original publications directly related to the Ph.D. thesis:................................................... 3

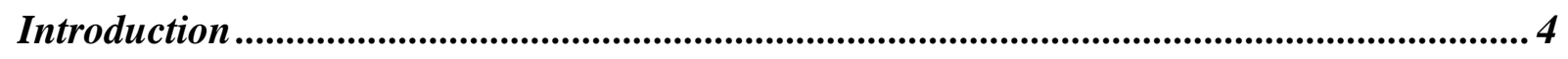

Motives behind childbearing ............................................................................................................................. 4

Definition of infertility and epidemiology of childlessness in developed and developing

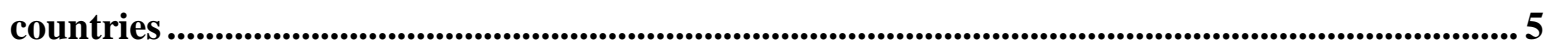

The psychological effects of unintended childlessness..................................................................... 7

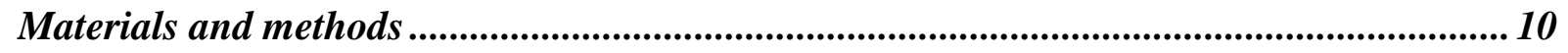

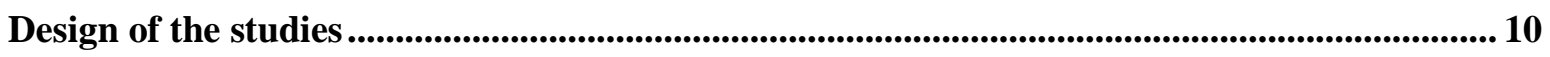

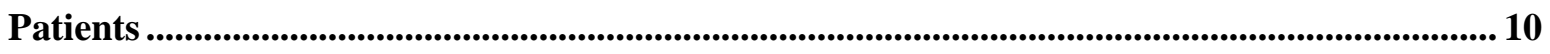

Instruments used in both of the studies.............................................................................................. 11

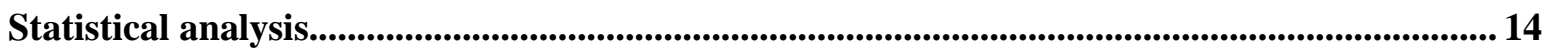

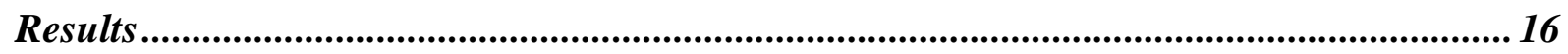

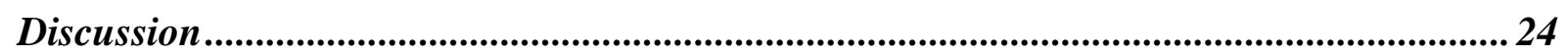

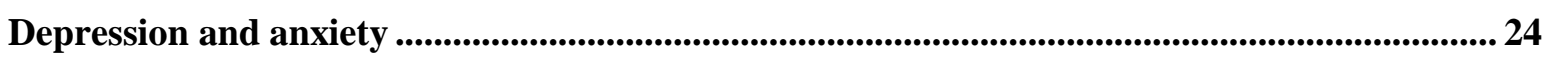

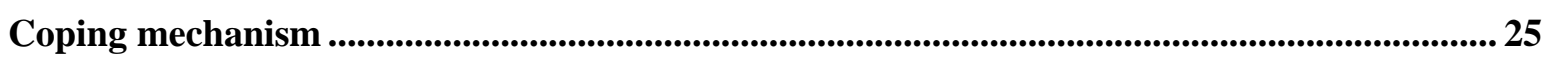

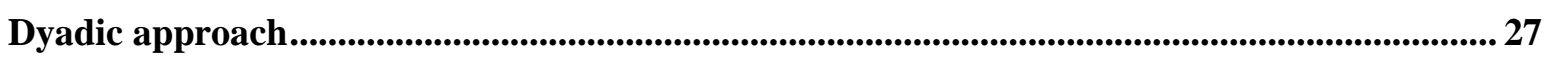

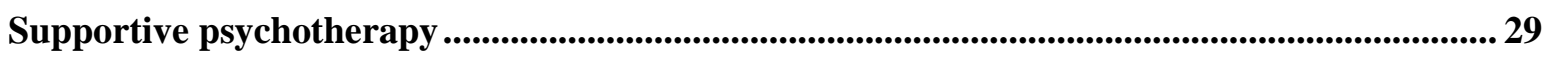

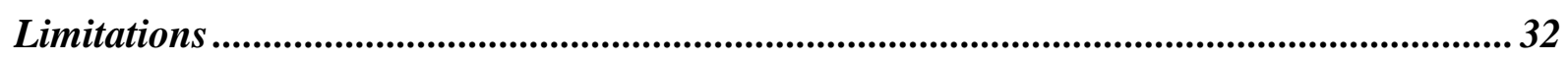

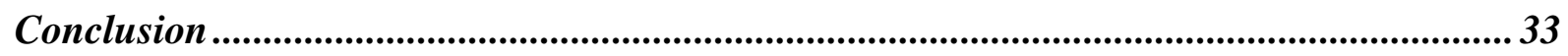

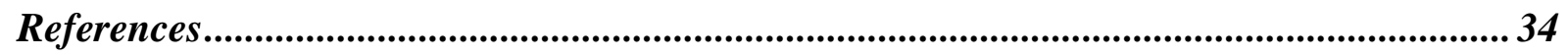




\section{Original publications directly related to the Ph.D. thesis:}

I. Hegyi BE, Kozinszky Z, Badó A, Dombi E, Németh G, Pásztor N. Anxiety and depression symptoms in infertile men during their first infertility evaluation visit. J Psychosom Obstet Gynaecol. 2019;40(4):311-317. doi:10.1080/0167482X.2018.1515906. Impact Factor: 2.327, Citation:1

II. Hegyi BE, Kocsis K, Király A, et al. Clustering Infertile Couples With Dyadic Approach: WHO-5-WBI as a Promising Tool for Assessing Psychological State. Psychol Belg. 2020;60(1):152-163. Published 2020 Jun 18. doi:10.5334/pb.53. Impact Factor: 1.524, Citation: 0

Cumulative impact factor of the publications directly to the thesis: 3.851 


\section{Introduction}

\section{Motives behind childbearing}

Childbearing has outstanding importance on cultural and individual aspects. The desire of having a child is multifactorial; its motives can be the age, marital status, cultural and economic expectations or religion affiliation as well. To sever or rank these motives is a difficult task. According to Kirkpatrick's model there are four main groups of the childbearing motives: (I.) Benefits, (II.) Circumstances, (III.) Individual needs and (IV.) Experiences [1] [2]. Based on this classification, benefits could be when the family as a production unit is growing by a child. Social support, tax benefit or fit to social expectations also can described as benefit. Circumstances are when the familiar connection is becoming stronger because of childbearing and when a child has a younger sister or brother. 'Individual needs' is having a child as a proof of effeminacy or masculinity, fulfilling earlier unfulfilled desires. Following the parental patterns can be classified as 'experiences' as well. A German study explored parental behavior and motives behind childbearing. They asked 785 women and 795 men about this topic [3]. Based on their results, emotional aspects are the most important motives in favor of having children, and financial restraints are most frequently cited as arguments against parenthood in German society.

Infertile women and men form a proper group for investigating motivations of becoming parents. These motivations can be hidden in healthy couples, but because of infertility, it manifests itself as unfulfilled desire [4]. Several studies compares men's motivation for fatherhood with women's motivation for motherhood among infertile couples [5]. Great proportion of these studies found that women's motivations are stronger than their partner's. In the earlier cited German study, when they examined only infertile patients, in line with literature, women's motives for having a child were stronger, but on the other hand, when they examined only the reproductive-aged subjects, the strength of the motives among men and women were nearly similar [3]. An Australian study also investigated the motives for paternity among men diagnosed with infertility [6]. Less, than the half of the participants agreed with the statement that women suffer more from the burden of childlessness than men, and 10 percent of subjects thought that paternity is the proof of their masculinity. Similar results were shown in a Dutch study in that they investigated childbearing motives among Dutch participants [7]. The participants reported desire for happiness as the main motive for having a child. $62 \%$ of 
men believed that they want a child as much as their partner, and $8 \%$ thought that their desire is stronger than their spouses.

\section{Definition of infertility and epidemiology of childlessness in developed and developing countries}

Infertility can be described as an inability to become conceived within one year despite regular unprotected intercourse [8]. Unintended childlessness is one of the biggest yet barely pronounced reproductive health problem in developed countries. Despite the fact that world's total population has almost tripled in the last seventy years, the total fertility rate has decreased during the same period [9]. The total fertility rate in a specific year is defined as the total number of children that would be born to each woman if she was to live to the end of her child-bearing years and give birth to children in alignment with the prevailing age-specific fertility rates [10]. According to the results of the 2015 Revision of World Population Prospects, Europe has the lowest fertility rate of 1.6 children per woman [11]. Hungary's results are in the line of the European numbers [12].

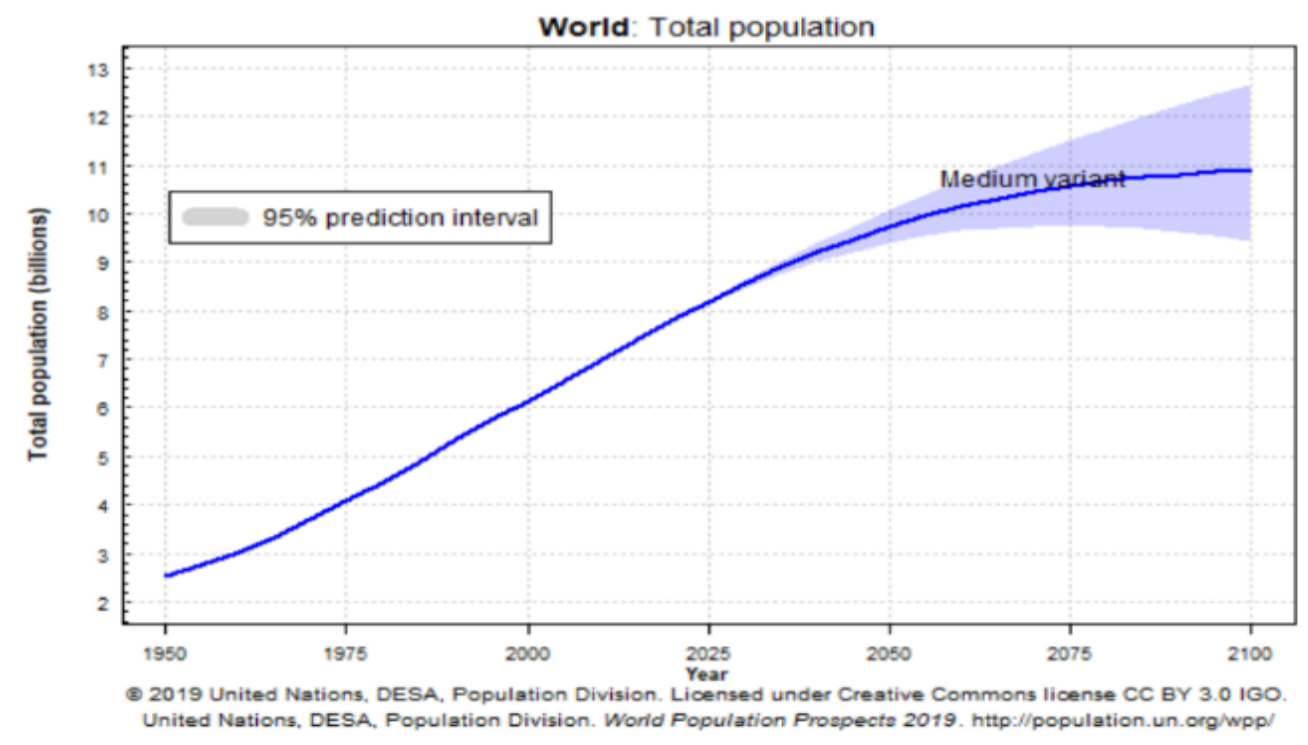

1. Figure: Changes in world population [11]. 


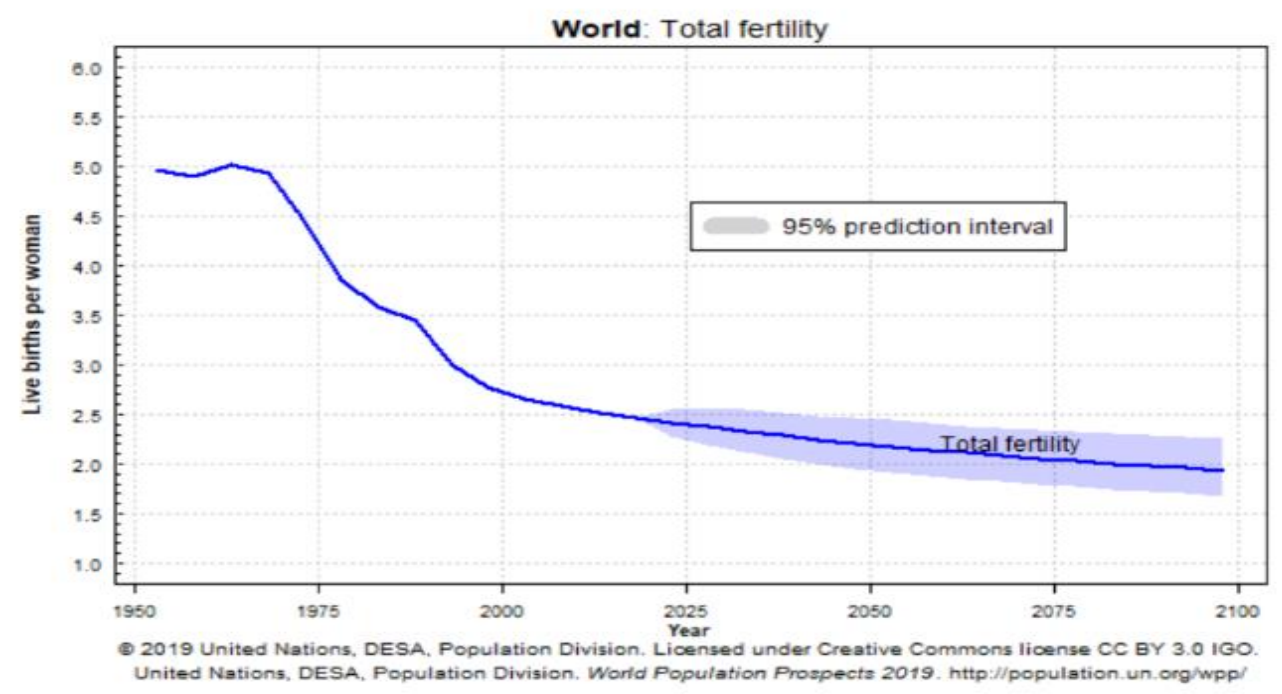

2. Figure: Changes of fertility rate on ratio of the world population [11].

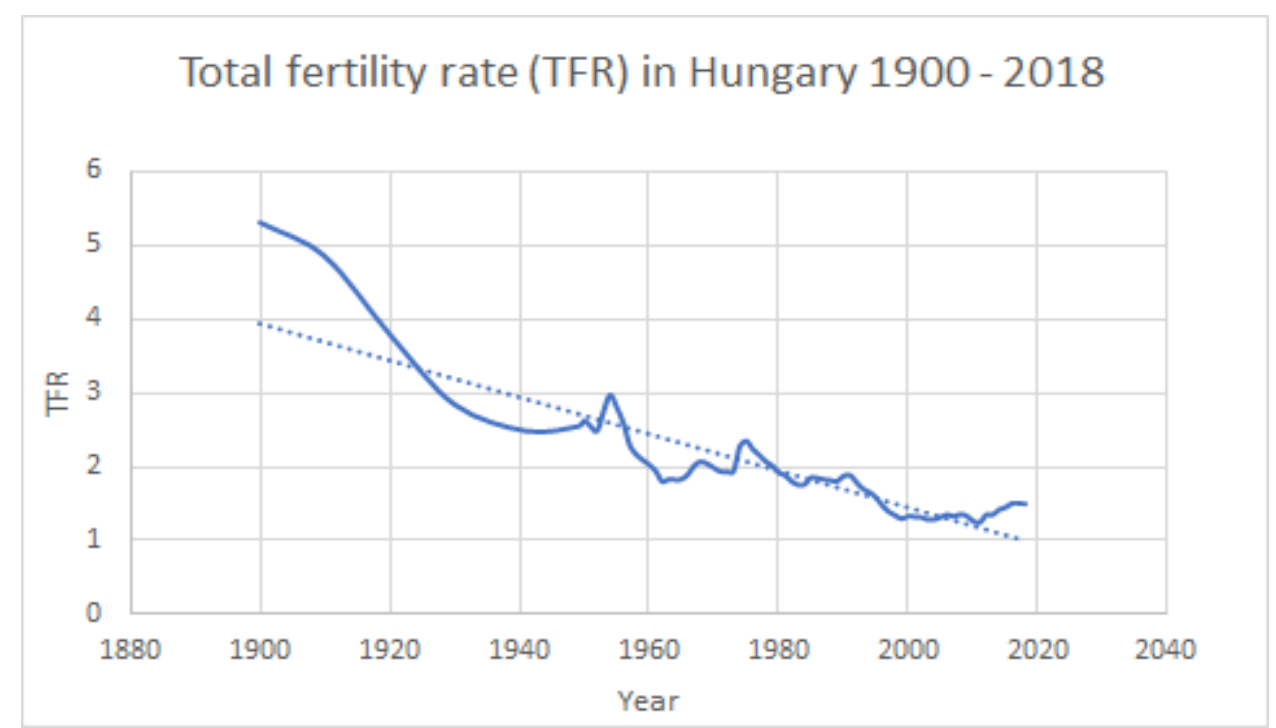

3. Figure: Total fertility rate in Hungary [12].

The past decade's fertility rate in most of the developed countries is lower than it could uphold the population. [13]. The reason of the decreasing fertility rate in high-income countries is usually influenced by economic and social factors; nevertheless undoubtedly some part of the childlessness is intentional. Besides social and economic factors, it is important to mention late childbearing tendency, female emancipation, easy availability of reliable contraception methods or opportunity for legal abortion [14]. Miettinen and Szalma examined trends and correlates of childlessness intentions in Europe considering the past decade [15]. They found 
on average that the childlessness as an individual preference is relatively rare in Europe; the rate of the voluntarily childless young adults aged 18 to 40 years was around from $1 \%$ to $6 \%$. The Eurobarometer data from 2011 confirm that childless Europeans are mostly not voluntarily childless [16] [17] . It proves that only a small proportion of childless men and women choose not to have child because they prefer for any reason a childfree lifestyle. The Eurobarometer data also indicate that the childlessness rate is higher among men than women in all countries.

Furthermore these days it became difficult to distinguish between the voluntary and involuntary childlessness, since a large number of reproductive-aged couples postpone realization of their desire to have a child and this may lead to a change from a voluntary to an involuntary childlessness [3]. The late, conscious childbearing, generally occurrs between the age of 35-40 years, can easily lead to reproductive health problems. According to StöbelRichter education about fertility as a resource should be promoted.

However, approximately 186 million people are facing the problem of infertility worldwide and in Hungary 9 percentage of the population are affected by unintended childlessness [18].

\section{The psychological effects of unintended childlessness}

As it was shown earlier, there are several motives in the background of childbearing, and the childlessness in the developed countries might unintended in most of the cases. Thus, it is clear that facing difficulties with fulfilling the desire of having a child have a serious impact on mental health of affected spouses. In the literature several studies are involved in the exploration of these psychological aspects affecting infertile couples. Those studies emphasize the importance of the psychological burden caused. In a study infertile couples were asked during the IVF treatment, and $50 \%$ of women and $15 \%$ of men reported that infertility is the heaviest crisis in their lives [19]. Nevertheless, the question arises what is the real crisis in this situation? In the literature the infertility-related psychological deviations are defined as a reaction to a distressful crisis. But it is separable really, which phenomenon is the source of distress: the unfulfilled desire for childbearing, or the assisted reproduction treatments, the diagnosis itself, patient stigmatization, or is it 'only' a reaction to the partner's behavior? However, it has shown that reproductive function is sensitive to psychological changes and distress can also negatively affect the process of in vitro fertilization programs [20]. Therefore, it would be crucial to monitor and screen the patient's mental status during infertility treatments. 
The main proportion of the literature focuses on the gender-differences of infertilityrelated mental health, especially focusing on women [21]. This attitude is understandable considering the psychological aspects of childlessness amongst men have been less evaluated compared to women in the past. In these studies, depression, anxiety and decreasing quality of life are mostly emphasized as the expression of mental burden [22]. In a Swedish study Volgsten at al. observed the prevalence of mental disorders among 1090 infertile woman and men [23]. They found that $10.9 \%$ of infertile women suffer from major depression, while only $5.1 \%$ of men are affected. In the same patient group, $14.8 \%$ of women and $4.9 \%$ of men showed symptoms of anxiety. A Hungarian study found similar results, they showed significant genderspecific differences in terms of quality of life and depression symptoms [22]. According to their results men felt the emotional, somatic, cognitive and social aspects of infertility less demanding than women. Nevertheless, it has to be emphasized that even though the infertilityrelated mental burden is undoubtedly more severe amongst women than men, the psychological status of men is also worst compared to the healthy population. In a polish study Drosdzol et al. compared the symptoms of depression and anxiety among 188 infertile male patients aged between 20-45 to the male members of 190 couples of the same age, who had at least one child [24]. According to their results, the scores of infertile men for both psychological disorders were higher than the fertile patients, moreover $15.6 \%$ of subjects suffered from mild depression. A Finnish study found similar results, when they compared the psychological status among random sample of Finnish people aged 30-44 years, some of whom had experienced, and some of whom had never experienced involuntary childlessness [25]. Based on their results, childless men with infertility experience have had a significantly poorer quality of life compared to men without infertility. However, the reaction to the distressful childlessness is not only an individual experience, it couples affect to each other's mental and psychological state as well. The importance of the literature-proved psychological effect is not only the decreasing wellbeing but this mental burden also influence the outcome of infertility treatment [20]. Nevertheless, the psychological aspects of childlessness amongst men have been less evaluated compared to women in the past. Furthermore, these previously published studies have usually been conducted at fertility clinics after some kind of therapeutic interventions, which might be a noteworthy influencing factor to the participant's psychological state as well. In these studies, the mental burden caused by childlessness cannot be distinguished from the effects of diagnosis or the medical intervention. Besides, studies focusing to the gender differences related to infertility examine the patients as individuals and not counts with the spousal effect on the psychological reaction. 
The main purpose of our studies was to investigate the less examined infertility-related psychological effects amongst men. In our first study we aimed to evaluate the consequences of unintended childlessness alone on the general anxiety and depression levels of the male partner. To minimize the psychological effect of infertility diagnosis and treatments, our study was carried out amongst men who were seeking an infertility evaluation for the very first time. In our second study we used dyadic approach to measure the spousal effect on mental health in connection with unintended childlessness. Our aim was also to emphasize the importance of a screening process related to the participant's psychological state, in which every patient should participate before infertility treatment, and to work out an alternative, reliable and effective clinical method for that. 


\section{Materials and methods}

\section{Design of the studies}

In our first study we aimed to investigate the general anxiety and depression levels in men presenting for infertility evaluation for the first time before starting the infertility workup. The possible connections between depressive and anxiety symptoms, the duration of infertility, and sperm characteristics were also investigated. After the performance of physical examination, but before semen was produced for sperm analysis, sociodemographic and medical data and information on lifestyle factors and fertility history were collected via multiple self-reported questionnaires. To assess the psychological distress visual analog scale (VAS) questionnaire was used, whilst to measure the rate of depression and anxiety a valid Hungarian version of the Beck Depression Inventory (BDI) and the Spielberger State-Trait Anxiety Inventory (STAI) was acquired.

In our second study we used a cross-sectional design with a dyadic approach to investigate how the psychological state related to infertility affects the spouses. During the examination period, the psychological state was measured by multiple questionnaires, like the BDI, STAI, well-being (WHO-5 Well-Being Index - WHO-5 WBI), general mental state (Symptom Check List- 90 Revised Test - SCL-90R), nicotine dependence (Fagerstrom Test for Nicotine Dependence - FTND), and alcohol dependence (Alcohol Use Disorders Identification Test - AUDIT) as well. Our primary outcome measures were the values of the level of depression, anxiety, general mental-health and well-being index. Accordingly, each case as one couple had two test results on each instrument. We identified the main characteristics of the formed clusters and examined whether the responses to the WHO-5 WBI fit the spouses into the formed groups. In addition, the data of WHO-5 WBI, as an independent variable, were not used in the calculation process of clustering.

\section{Patients}

In our first study heterosexual men seeking a fertility evaluation at our Andrology Unit between September 1, 2013 and March 1, 2014 were enrolled. Only first-time patients were enrolled provided they had not previously participated in any andrological testing or in any other examination related to infertility. Due the immediate access to fertility specialist in Hungary (both gynecologists and male fertility specialists), general practitioners are not routinely involved in fertility evaluation and treatment. The female partners of the participants participated in ongoing parallel infertility investigations, but in accordance with our clinical 
routine, neither tubal patency testing nor any type of assisted reproductive technique was performed prior to a sperm analysis on the spouse or partner. It has to pointed out, that the patients initiated the investigations themselves or according to the advice of the partner's gynecologist. Thus, at the time of enrollment, the fertility status of the couple was unknown. Exclusion criteria were presence of any previously diagnosed psychological disorder(s). From all of our patients informed consent was obtained and the study was conducted in accordance with the ethical standards of the Helsinki Declaration of 1975, as revised in 2000, as well as the study protocol was approved by the Regional and Institutional Human Medical Biological Research Ethics Committee.

In our second investigation we have examined infertile couples who were attended to our Andrology Outpatient Clinic during a time period from August 2017 to April 2019. At this time, it was not a criterion to be a first-time patient. Exclusion criteria were presence of any previously diagnosed psychological disorder(s) and/ or any severe case in life history. As in our first study, patients informed consent was obtained and the study was conducted in accordance with the ethical standards of the Helsinki Declaration of 1975, as revised in 2000, as well as the study protocol was approved by the Regional and Institutional Human Medical Biological Research Ethics Committee.

\section{Instruments used in both of the studies}

\section{Visual Analog Scale (VAS)}

A visual analog scale assesses the psychological distress of the present evaluation on a numerical scale from 0 to 10 , where 0 means no distress and 10 means unbearable distress. Single-item measures, like this, in which patients mark their subjective mental status on a visual scale, afford simple and rapid administration, and increased comprehension [26]. We used this instrument only in our first study.

\section{Hungarian version of Shortened Beck's Depression Inventory (BDI) (Beck et al., 1961)}

9-item shortened version of Beck Depression Inventory with 21 questions, a 4-point (from 0 to 3) Likert scale questionnaire asks for symptoms of depression such as social withdrawal, indecision, sleep disturbance, fatigue, excessive anxiety due to physical symptoms, disability, pessimism, satisfaction and lack of joy and self-blame. The total score is 63 points. 
The BDI results were rated as follows: 0-9: no depressive symptoms; 10-18: mild depressive symptoms; 19-29: moderate depressive symptoms; and >30: severe depressive symptoms. We used this instrument in both of our studies. In our second study, BDI served as a dependent variable of cluster analysis.

Hungarian version of State-Trait Anxiety Inventory Form Y-1 and Form Y-2 (STAI) (Spielberger, Lusbene \& Vagg 1983)

The State-Trait Anxiety Inventory being widely used in clinical practice and research. It is a short self-report questionnaire to evaluate the level of anxiety and was designed by Spielberger and colleagues. Form STAI-State and STAI-Trait measure state and trait anxiety with 20-20 items. In Hungary, the STAI-State has a normal value for women at 42,6 (SD \pm $10,79)$ points, and normal value for men at 38,4 points $(\mathrm{SD} \pm 10,66)$. In the STAI-Trait questionnaire, the normal value for women is $45,3(\mathrm{SD} \pm 7,97)$ point and the normal value for men is 40,9 ( $\mathrm{SD} \pm 7,78)$ points (Sipos, Sipos \& Spielberger 1994). Higher scores refer to higher level of anxiety. Some authors make allowance for STAI as a measurement tool of general negative affect, for instance anxiety, depression and well-being. In our first study, we used only STAI-Trait to mesure the trait anxiety of the patients. In our second study, we worked with both type of this instrument. STAI-State and STAI-Trait served as dependent variables of cluster analysis.

Hungarian version of Symptom Checklist-90 Revised test (SCL-90R) (Derogatis et al., 1974)

The SCL-90R is a multidimensional self-reported questionnaire to assess 9 different dimensions: somatization, obsessive-compulsive, interpersonal sensitivity, depression, anxiety, hostility, phobic anxiety, paranoid ideation, and psychotic symptoms. Each dimension can be interpreted separately. Total scores can range from 0 to 450, higher scores in SCL-90R refer to worse general psychological state. To determine general mental health, we calculate the Global Severity Index (GSI) (Total Score/90), which value is $0,62(\mathrm{SD} \pm 0,50)$ in the validated normal Hungarian sample. We used this instrument only in our second study. SCL-90R served as a dependent variable of cluster analysis in it.

Hungarian version of WHO-5 Well-Being Index (WHO-5-WBI) (Heun et al., 1999) 
The World Health Organization-Five Well-Being Index is a short self-reported questionnaire containing 5 items to evaluate current mental well-being in a time period two weeks prior the completion. The questionnaire is based on the WHO-10 Well-Being Index and was developed by Bech in collaboration with the World Health Organization. The instrument contains 5 different questions about subjective psychological well-being as daily activity; being vigorous; being cheerful; being calm, relaxed; and general interest in life. Each item is scored from 0 to 3, the maximum possible score is 15 . The average score of men is 8,2 ( $\mathrm{SD} \pm 2,7)$, for women is $7,4(\mathrm{SD} \pm 3,8)$, measured on a validated Hungarian sample. Higher WHO-5-WBI scores mean better well-being of the subjects. We used this instrument only in our second study. The test was used as independent variable while assessing its diagnostic efficacy.

\section{Hungarian version of Alcohol Use Disorders Identification Test (AUDIT) (Saunders et al., 1993)}

AUDIT is a 10-item short self-reported questionnaire to examine the frequency of alcohol consumption ( 3 questions), the rate of alcohol dependence (3 questions) and the derived problems due to the alcohol consumption as well (4 questions). Each question is scored from 0 to 4 , the maximum possible score is 40 . AUDIT provides a simple method of early detection of hazardous and harmful alcohol use in primary health care. Higher scores (above 8 points) in AUDIT refer to more severe alcohol dependence. We used this instrument only in our second study.

Hungarian version of Fagerstrom Test for Nicotine Dependence (FTND) (Fagerstrom, 1978)

The Fagerstrom Test for Nicotine Dependence is a 6-item short self-reported questionnaire to assess the rate of physical addiction to nicotine. The inventory briefly covers smoking habits, such as using a first cigarette a day, smoking control or smoking during illness. The possible maximum score is 10 , from 0 to 2 points there is no sign of nicotine dependence. Higher Fagerstrom scores refer to more intense addiction to nicotine. We used this instrument only in our second study as well. 


\section{Statistical analysis}

In the first study statistical analyses were performed with SPSS 17.0 for Windows (SPSS Inc., Chicago, IL, USA). The Shapiro-Wilk test and analyses of the Q-Q plot diagrams demonstrated that age, body mass index (BMI), VAS scores, BDI scores, sperm characteristics, and the duration of infertility were not normally distributed while the distribution of the STAI results was normal.

The correlations between the duration of infertility and the VAS, BDI, and STAI results were determined using regression analyses. In addition, the correlation between the BDI and STAI scores and sperm characteristics were also analyzed. A multivariable linear regression analysis was also controlled for age, BMI, smoking, and the number of children. Correlation coefficients (B) were calculated for both the univariate and multiple linear regression, whereas standardized coefficients (ß) were given for univariate analyses and semipartial correlations (r) for multivariable regression. To express the results in terms of the proportion of explained variance, the square of the standardized coefficient and the square of the semipartial correlation were calculated. All variables which did not follow the Gaussian distribution were transformed logarithmically $(\log 10(x t ̧ 1))$ so that they could be included in the regression model. The distributions of BDI and STAI score categories were compared with the duration of infertility categories using the chi-square trend test. The distributions of the VAS scores among the three subgroups of the duration of infertility were assessed with the analysis of variance (ANOVA) test. Statistical significance was defined at the two-sided pL'.05 level.

In the second study, data of each couple, both male and female were ordered into the same case. Considering the fact, that the scores of WHO-5-WBI for males and WHO-5-WBI for females are independent variables in the classification process, we examined them first for normality and outliers. We experienced one outlier on the scale of WHO-5-WBI among females. Avoiding the distortion, we excluded this case (couple) from the analysis. Health related additional instruments, Fagerstrom and AUDIT results were analyzed as basic characteristic variables.

We found that WHO-5-WBI scores differed from normal distribution for both genders, therefore Logistic Regression was used in the later statistical analysis to evaluate its predictive effectiveness.

To determine the interdependence between the male and female partner's psychological involvement (e.g.: depression, anxiety, general mental health), we separated the couples into two clusters, based on BDI-male, BDI-female, STAI-State-male, STAI-State-female, STAI-Trait-female, SCL-90R-male, SCL-90R-female results. Two-Step cluster analysis was carried out consecutively, 
because it considered as a robust method against a lack of normal distribution and outliers. We also determined the main characteristics of the formed groups.

As previously defined, the reliability of WHO-5-WBI classification was tested with Logistic Regression on the clusters. Reaffirming the diagnostic values of WHO-5-WBI, we performed ROCanalysis and determined the effectiveness of WHO-5-WBI.

Data were analyzed using the Statistical Package for Social Sciences (SPSS 25.0.0 for Windows, SPSS Inc., http://www.spss.com). 


\section{Results}

A total of 117 patients were invited to take part in our first study, but four (3.4\%) patients declined to complete the questionnaire; hence, it was the results from 113 patients that were analyzed. All of them were Caucasian. The mean age of the study population was 33.3 (range: 23-54) years. Furthermore, the mean duration of attempting to achieve pregnancy was 16.3 (range: 0-96) months. The mean age of their partners was 31.7 (range: 20-47) years, and the duration of the patients' relationship was 5.9 (range: 0.25-27) years on average. With regard to marital status, $42.5 \%$ were married and $57.5 \%$ lived in partnerships. Only 10 men (8.8\%) had a child from the present relationship and five (4.4\%) from a previous relationship. Furthermore, 12 patients $(10.6 \%)$ had a partner who had a spontaneous abortion in the present relationship. The average frequency of sexual intercourse was 2.7 (range: 0.5-8) times a week, with only two patients $(1.7 \%)$ reporting mild erectile dysfunction. Regarding to the questionnaires, the BDI was completed entirely in 110 cases (97.3\%), whereas both the STAI and VAS were completed in 102 cases (90.3\%). The mean results for the BDI and STAI were 2.24 (standard deviation (SD: \pm 3.18 ) and 33.74 (SD: \pm 8.04 ), respectively. No patient was registered with high BDI scores (above 19 points), indicating moderate or severe depressive symptoms. The VAS finding relating to the self-reported psychological distress of the present examination was 2.52 on average (SD: \pm 2.04 ; range: $1-8$ ). In univariate and multivariable analyses, significant correlations emerged with low regression coefficients between the BDI scores and the duration of infertility (pL'.042, BL'0.207, B2L'0.038 and pL'024, BL'0.241, r2L'0.047, respectively), whereas the STAI score showed no correlation (pL'.120, BL'0.005, B2L'0.024 and pL'.142, BL'0.005, r2L'0.022; respectively). The result for the VAS tended to be higher with the duration of childlessness (pL'.044, BL'0.23, B2L'0.023), but the correlation became non-significant when we controlled for other factors in the multivariable analysis (pL'.261, BL'0.178, B2L'0.013) (Table 1.) 


\begin{tabular}{|c|c|c|c|c|c|c|}
\hline & \multicolumn{3}{|c|}{$\begin{array}{c}\text { Univariate } \\
\text { linear regression }\end{array}$} & \multicolumn{3}{|c|}{$\begin{array}{c}\text { Multivariable } \\
\text { linear regression }\end{array}$} \\
\hline & $p$ value & $B$ & $B^{2}$ & $p$ value & $B$ & $r^{2}$ \\
\hline BDI score & 0.042 & 0.207 & 0.038 & 0.024 & 0.241 & 0.047 \\
\hline STAI score & 0.120 & 0.005 & 0.024 & 0.142 & 0.005 & 0.022 \\
\hline VAS score & 0.044 & 0.23 & 0.023 & 0.261 & 0.178 & 0.013 \\
\hline
\end{tabular}

Table 1.: Correlation between the BDI, VAS, and STAI scores, and the duration of infertility $(\mathbf{N}=113)$. B: regression coefficient, $r$ : semi-partial correlation, $\beta$ : standardized coefficient.

There were significant correlations between the STAI and VAS scores (univariate analysis: p<.001; BL'19.270, B2L'0.174 and multivariable analysis: $\mathrm{p}<.001 ;$ BL20.228, r2L'0.181) and between STAI and BDI scores (univariate analysis: p<.001, BL'11.192, ß2L'0.153 and multivariable analysis: $\mathrm{p}<.001$; BL'11.532, r2L'0.130) (not shown in the tables). The frequency of mild symptoms of depression (BDI score: 10-18) increased significantly as the duration of infertility grew longer (groups of 0-12 months, 13-24 months and >24 months) (pL'.006) while the incidence of an abnormal level of anxiety (STAI score >49) (pL'.353) and self-reported psychological distress tied to the examination (VAS scores) (pL'.086) did not differ in these three groups (Table 2.). No sperm variable showed a correlation with the BDI, STAI, or VAS scores (not shown in the tables).

\begin{tabular}{|c|c|c|c|c|c|}
\hline \multirow[b]{2}{*}{$\begin{array}{l}\text { Duration of } \\
\text { childlessness (months) }\end{array}$} & \multicolumn{2}{|c|}{ BDI score $(n=110)$} & \multicolumn{2}{|c|}{ STAI score $(n=102)$} & \multirow{2}{*}{$\begin{array}{l}\text { VAS score }(n=102) \\
\begin{array}{c}\text { Average result } \\
\text { of VAS**** }\end{array}\end{array}$} \\
\hline & $\begin{array}{c}\text { Patients without } \\
\text { depressive } \\
\text { symptoms }(B D \mid<10)\end{array}$ & $\begin{array}{l}\text { Patients with depressive } \\
\text { symptoms (BDI: } \geqq 10)^{*}\end{array}$ & $\begin{array}{c}\text { Number of patients } \\
\text { without } \\
\text { anxiety }(S T A \mid<50)\end{array}$ & $\begin{array}{l}\text { Number of patients with } \\
\text { clinically relevant level of } \\
\text { anxiety }(S T A I \geq 50)^{* *}\end{array}$ & \\
\hline $0-12$ & 58 & $0(0 \%)$ & 52 & $2(3.7 \%)$ & 2.13 \\
\hline $13-24$ & 37 & $2(5.1 \%)$ & 34 & $2(5.5 \%)$ & 2.92 \\
\hline$>24$ & 10 & $3(23.1 \%)$ & 11 & $1(8.3 \%)$ & 3.10 \\
\hline Total & 105 & $5(4.5 \%)$ & 97 & $5(4.9 \%)$ & 2.52 \\
\hline$p$ value & \multicolumn{2}{|c|}{.006} & \multicolumn{2}{|c|}{.353} & .740 \\
\hline
\end{tabular}

Table 2.: Incidence of patients with depressive symptoms, clinically relevant level of anxiety, and average VAS results according to childlessness duration in subgroups.

In our second study also all the questionnaires were self-completed and $61 \%$ of the infertile couples agreed to participate in the study and complete the questionnaires. Altogether, 65 infertile couples were enrolled. Later, we excluded one outlier couple during the statistical data analysis. Accordingly, the final calculations were performed with 64 case $(n=128)$. 
The results of the questionnaires in our study population are shown in (Table 3). The average age of men was 37.34 years $( \pm 5.84 \mathrm{SD})$; of women 34.07 years $( \pm 0.06 \mathrm{SD})$. In terms of education, most common highest level of education was high school degree for both genders (32.8\% of men; $37.5 \%$ of women). Mean BDI results were 3.59 for males and 5.17 for females. Mean scores of STAI-Trait and STAI-State tests were 33.61 and 34.73 for men, 37.36 and 37.31 for women. Mean SCL-90R-GSI was 0.33 for both genders, WHO-5-WBI mean scores was similar, 9.59 for men and 9.56 for women. With regard to smoking (Fagerstrom) and alcohol consumption (AUDIT), $68.8 \%$ of men were non-smoker, $28.3 \%$ were moderate smoker, the rest of them (2.9\%) reported severe nicotine dependency. Regarding the women, $75.0 \%$ were non-smoker, $25.0 \%$ were moderate smoker and no serious nicotine addict was registered. Among men in terms of alcohol consumption, $12.5 \%$ were non-drinker, $71.9 \%$ were moderate drinker, the remainders (15.6\%) were facing serious alcohol problems. In parallel, $25 \%$ of women do not consume alcohol, $68.7 \%$ can be identified as moderate drinker, the remainders (6.3\%) having serious alcohol problems.

\begin{tabular}{|c|c|c|c|c|c|c|c|}
\hline & \multicolumn{3}{|c|}{ Mean $( \pm \mathrm{SD})$} & \multicolumn{2}{|c|}{$\begin{array}{l}\text { Differences } \\
\text { between male and } \\
\text { female }\end{array}$} & \multicolumn{2}{|c|}{$\begin{array}{l}\text { Test of Normality } \\
\text { (Saphiro-Wilk) } \\
\text { value }\end{array}$} \\
\hline & Couples & Male & Female & $\begin{array}{l}\mathrm{t} \\
(\mathrm{df}=63)\end{array}$ & $\mathrm{p}$ & Male & Female \\
\hline $\mathrm{n}$ & 64 & 64 & 64 & & & & \\
\hline Age & $\begin{array}{l}35.71 \\
(0.59)\end{array}$ & $\begin{array}{l}37.35 \\
(0.73)\end{array}$ & $\begin{array}{l}34.08 \\
(0.60)\end{array}$ & 5.129 & $<.001 *$ & .655 & .248 \\
\hline Fagerstrom & $\begin{array}{l}1.27 \\
(0.24)\end{array}$ & $\begin{array}{l}1.42 \\
(0.29)\end{array}$ & $\begin{array}{l}1.10 \\
(0.25)\end{array}$ & 1.186 & .240 & $<.001$ & $<.001 *$ \\
\hline AUDIT & $\begin{array}{l}3.10 \\
(0.38)\end{array}$ & $\begin{array}{l}3.96 \\
(0.49)\end{array}$ & $\begin{array}{l}2.25 \\
(0.34)\end{array}$ & 4.338 & $<.001 *$ & $<.001$ & $<.001^{*}$ \\
\hline
\end{tabular}




\begin{tabular}{|c|c|c|c|c|c|c|c|}
\hline BDI & $\begin{array}{l}4.38 \\
(0.50)\end{array}$ & $\begin{array}{l}3.59 \\
(0.59)\end{array}$ & $\begin{array}{l}5.17 \\
(0.66)\end{array}$ & -2.110 & $.039 *$ & $<.001$ & $<.001 *$ \\
\hline STAI-State & $\begin{array}{l}36.02 \\
(1.02)\end{array}$ & $\begin{array}{l}34.73 \\
(1.20)\end{array}$ & $\begin{array}{l}37.31 \\
(1.22)\end{array}$ & -1.966 & .054 & .008 & .327 \\
\hline STAI-Trait & $\begin{array}{l}35.48 \\
(0.91)\end{array}$ & $\begin{array}{l}33.60 \\
(0.94)\end{array}$ & $\begin{array}{l}37.35 \\
(1.13)\end{array}$ & -3.759 & $<.001^{*}$ & .196 & .060 \\
\hline $\begin{array}{l}\text { SCL-90-R } \\
\text { (GSI) }\end{array}$ & $\begin{array}{l}0.33 \\
(0.25)\end{array}$ & $\begin{array}{l}0.28 \\
(0.29)\end{array}$ & $\begin{array}{l}0.37 \\
(0.29)\end{array}$ & -2.392 & $0.020 *$ & $<.001$ & $<.001 *$ \\
\hline $\begin{array}{l}\text { WHO-5- } \\
\text { WBI }\end{array}$ & $\begin{array}{l}9.57 \\
(0.30)\end{array}$ & $\begin{array}{l}9.59 \\
(0.40)\end{array}$ & $\begin{array}{l}9.56 \\
(0.29)\end{array}$ & .090 & .928 & .055 & $.031 *$ \\
\hline
\end{tabular}

Table 3: Descriptive statistics showing the main characteristics of domains for mental health between males and females. [BDI (Beck's Depression Inventory), STAI (State-Trait Anxiety Inventory), SCL-90-R (Symptom Checklist-90-Revised test), WHO-5-WBI (WHO-5 Well-Being Index)] and level of nicotine (Fagerstrom Test for Nicotine Dependence) and alcohol dependency [AUDIT (Alcohol Use Disorders Identification Test)], with test of normality. Significant ' $p$ values' are signed with *.

Two-step Cluster Analysis generated two distinct cluster groups with highly homogenous patterns of health-related psychological characteristics. Of the 64 couples, $53.1 \%$ $(n=34)$ can be classified as Cluster 1: "Infertile couples with high values on mental health inventories" and $46.9 \%(\mathrm{n}=30)$ as Cluster 2: "Infertile couples with low values on mental health inventories".

Cluster 1 produced higher levels on health-related and psychologically relevant questionnaires, in contrast, the couples in Cluster 2 showed lower results. According to the cluster analysis process, all variables showed a significant difference between the two clusters. In the Cluster 1, for both men and women higher average levels of anxiety were experienced on STAI-Trait (STAI-Trait Cluster 1: $m e n=38.32$; women=43.03; Cluster 2: men=28.27; 
women=30.93). STAI-State also showed elevated scores by each gender in Cluster 1 (STAIState Cluster 1: men=40.44; women=43.00; Cluster 2: $\operatorname{men}=28.27$; women=30.87). BDI results also suggested that members of the Cluster 1 experience inferior conditions compared to the Cluster 2 group (BDI scores, Cluster 1: men=5.97; women=7.94; Cluster 2: men=0.90; women=2.03). Specifying the mental-health condition in general (measured with SCL-90-R), we experienced higher total scores for each gender (GSI scores: men=0.45; women=0.55) in Cluster 1 , compared to Cluster 2 (men=0.10; women=0.18). In addition, men in Cluster 1 displayed higher risk for alcohol dependency (AUDIT Cluster 1: $\mathrm{t}(62)=49.505, p=0.021$ ). The age and the level of nicotine addiction showed no significant difference between the clusters. The results are summarized in (Table 4).

Mean Scores

Cluster 1

Cluster 2

Between

Infertile couples

with higher risk of

mental health

issues

Infertile couples

cluster

with lower risk of

differences

mental health issues

( $p$-value)

Male Female $p$-value Male Female $p$-value

$\mathrm{n}$

$34 \quad 34$

30

30

STAI-

$\begin{array}{llllllll}\text { Trait } & 38.32 & 43.03 & .958 & 28.27 & 30.93 & .481 & <.001 *\end{array}$

STAI-

State

$40.44 \quad 43.00 \quad .287$

$28.27 \quad 30.87$

.371

$<.001 *$ 
SCL-

$\begin{array}{llllllll}\text { 90-R } & 0.45 & 0.55 & .331 & 0.10 & 0.18 & .247 & <.001 * \\ (\mathrm{GSI}) & & & & & & & \\ & & & & & & & \\ \text { BDI } & 5.97 & 7.94 & .624 & 0.90 & 2.03 & <.001 * & <.001 *\end{array}$

Table 4: The main features of calculated clusters showing significant differences on mental health scales. [BDI (Beck's Depression Inventory), STAI (State-Trait Anxiety Inventory), SCL-90-R (Symptom Checklist-90-Revised test)] estimating higher or lower theoretical probability of occurring mental health problems. Within cluster comparison suggests interdependence between male and female partners, namely we found no significant differences, only in the case of BDI within Cluster 2. Significant ' $p$ values' are signed with *.

Logistic regression analysis was performed to assess the predictive efficiency of WHO5-WBI on the likelihood that the infertile couples would be classified into the Cluster 1 or Cluster 2. Regarding to this, we used the cluster membership as the dependent variable in the logistic regression. The model representing predictors was statistically significant ( $\chi 2$ (df 2 , $\left.\mathrm{n}_{\text {total: }}: 64, \mathrm{n}_{\text {clusterl }}: 26, \mathrm{n}_{\text {cluster: }} 38\right)=14.59, p<0.0001$ ), explaining that the model was able to distinguish between infertile couple who were separated into clusters based on their results of BDI, STAI, SCL-90R (Table 5). The results also show that WHO-5-WBI-male and WHO-5WBI-female, as independent predictor variables, specify the regression with a significantly negative coefficient (WHO-5-WBI-male: 0.298, $p=0.016$; WHO-5-WBI-female: 0.474 , $p=0.008$ ). Congruent association of predicted probabilities and observed responses was $75.0 \%$, which is further evidence of the effectiveness of the classification. Despite the fact that couples were interpreted as cases (dyads), the values of both women and men, had a reliable diagnostic model for the couple's mental state. 


$\begin{array}{lllll}\text { Estimator effect } & \text { B } & \text { df } & \text { Wald } \chi^{2} & \text { Pr }>\chi^{2}\end{array}$

\begin{tabular}{lllll}
\hline WHO-5-WBI-male & -.298 & 1 & 5.837 & $.016 *$ \\
WHO-5-WBI-female & -.474 & 1 & 6.943 & $.008 *$ \\
\hline
\end{tabular}

Table 5: Results show significant estimator effect for both variables (WHO-5WBI-male and WHO-5-WBI-female). Suggesting the efficacy of WHO-5-WBI (WHO-5 Well-Being Index) scale while classifying cases into the generated clusters. Based on this, we can conclude that WHO-5-WBI has a good predictive effect deciding later cluster membership. Significant ' $p$ values' are signed with *.

For further confirmation, and showing the tradeoff between sensitivity and specificity, a Receiver Operating Characteristic curve was calculated. The appropriate ROC curve was

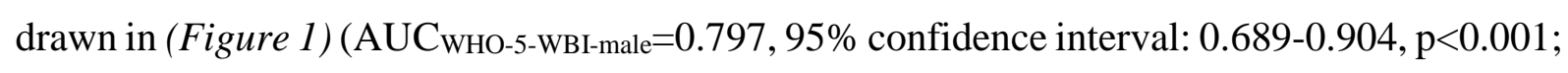
AUC $_{\text {WHO-5-WBI-female }}=0.804,95 \%$ confidence interval: $\left.0.699-0.910, \mathrm{p}<0.001\right)$. The ROC analysis suggests that WHO-5-WBI as a diagnostic test has separative ability to discriminate between cluster memberships. 


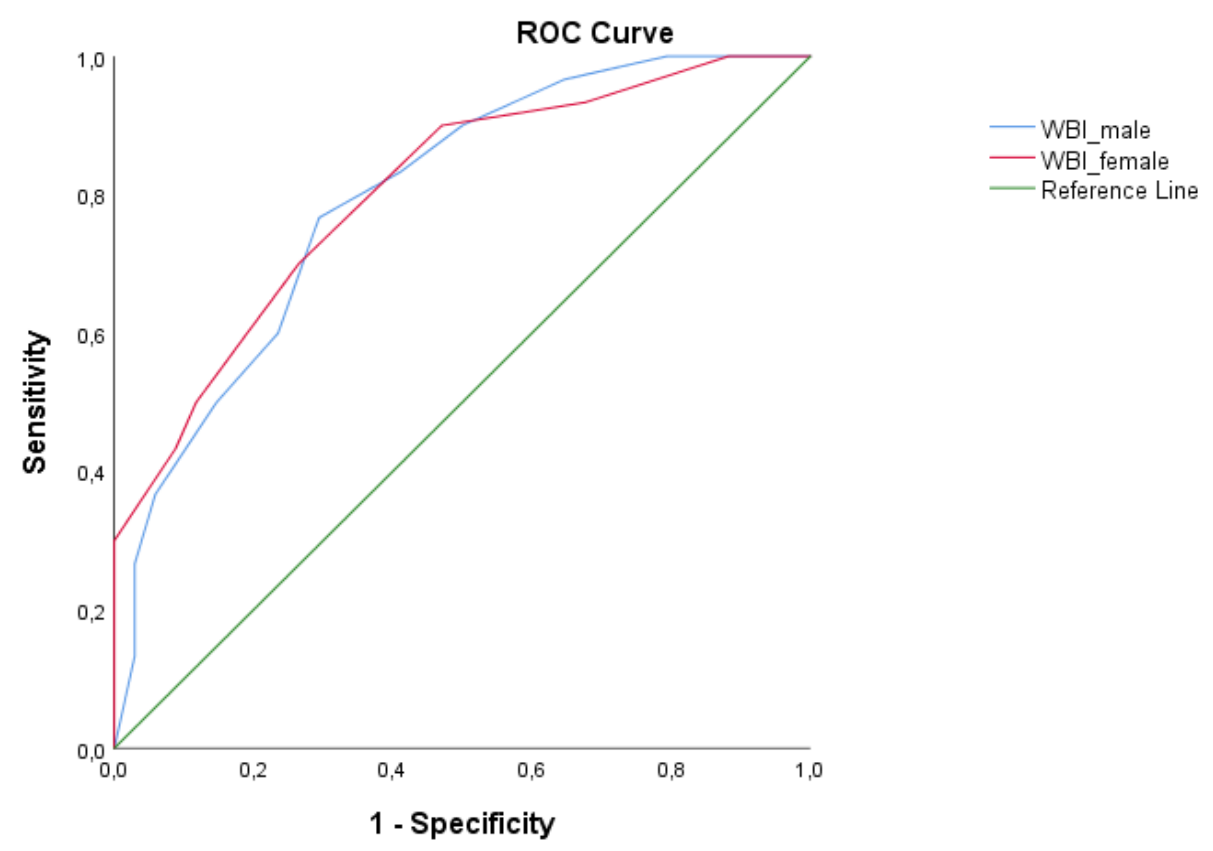

Figure 1: Result of the logistic regression analysis to assess the efficacy of WHO-5-WBI in classifying infertile couples. The logistic regression analysis showed that both the values of the WHO-5-WBI questionnaire of male and female spouses were reliable predictors for the infertile couple's mental state (The curve of WBI_male (blue line), and WBI_female (red line) do approximate to higher sensitivity as well as to lower 1-specificity values). [WHO-5-WBI (WHO-5 Well-being Index), ROC Curve (Receiver Operating Characteristic Curve), WBI_male (WHO-5-WBI values in male spouses), WBI_female (WHO-5-WBI values in female spouses)]. 


\section{Discussion}

The motives behind childbearing are determined by several factors amongst men and women. In the background of these intentions, individual, social, economic or religion related motifs could be mentioned [27]. Unfulfilling this multifactorial desire of having a child can impose serious psychological burden to the affected spouses [28]. Based on a review, that summarized the last twenty year's publications in this topic, studies related to infertility mostly discussed the aspects of psychological differences between genders, a smaller part of the researches focused on the aspect of psychological burden on couples, and only some research emphasized the emotional burden on males separately [21].

\section{Depression and anxiety}

Relating infertility, the most frequently experienced psychological disorders amongst infertile couples are anxiety and depression, hence a significant part of the literature focuses on the presence of these symptoms [21].

Therefore, the purpose of our first study was to investigate the effect of the duration of unintended childlessness on the psychological condition of men at the start of the infertility evaluation. In this study we aimed to distinguish the consequences of unintended childlessness from the psychological effect of infertility treatments and the diagnosis itself. To measure the correlation between the duration of childlessness and the extent of distress factors was also our purpose. In our study mild depressive symptoms were found (BDI < 19 point) in $4,5 \%$ of the patients. This proportion is nearly equal with the percent of men with moderate or severe depression symptoms $(4,3-5,1 \%)$ during infertility treatment in other researches [29] [30]. According to these results we can assume that depressive symptoms are increasing as a consequence of infertility treatments. Although the literature lacks this topic amongst men, the female gender has been examined by some studies still. The aim of a before-after study was to analyze the Beck Depression Inventory score at the beginning and the end of infertility treatment among 251 women who had been visited for assisted reproductive technology infertility treatment [31]. Their results showed that BDI score after treatment was strongly connected to the BDI score before treatment, the result of therapy and to the duration of infertility. Another study that investigated spousal reactions aimed to evaluate and compare state-trait anxiety and depression levels in couples undergoing ART treatments for the first time and in a follow up phase repeatedly [32]. This research confirmed the hypothesis that assisted reproduction treatments increase the spousal depression symptoms. 
Our study also found significant correlation between the depression symptoms and the duration of childlessness amongst the examined men, showing that the main determining factor of depression was the duration of childlessness. In numbers, $23,1 \%$ of men who suffered from unintended childlessness longer than 24 months had mild depression. Similar results had another study, that enrolled 370 infertile women to investigate infertility-related depression using BDI. According to their results depression had a significant relation with cause of infertility, duration of infertility, educational level, and job of women [33]. By measuring the connection between duration of childlessness and depression symptoms another study also found correlation amongst 114 infertile men [34].

As a result of our study we did not found significant correlation between anxiety symptoms and the duration of childlessness, prior the participants started the infertility treatments. This outcome is not in the line with the literature, where almost all studies found correlation between these two factors. [21, 23, 28]. According to this it can be assumed that the presence of anxiety symptoms is mostly linked to the infertility treatments. This presumption is proved by Zorn at al.'s study, in which they found significant correlation between IVF and the level of anxiety [35].

In our second study we examined the mental status of couples suffering from infertility. In this study we used questionnaires describing depression and anxiety symptoms also. The results revealed that infertile couples could be separated based on the scores of SCL-90-R, STAI-State and STAI-Trait and the BDI. We were able to identify two, significantly different clusters, one (Cluster 1) with relatively high and other (Cluster 2) group with relatively low scores, and corresponding to this clustered groups, a two different group with a relatively low and high level of anxiety and depression symptoms. In Cluster 1, for both men and women higher average levels of anxiety were experienced on STAI-Trait (STAI-Trait Cluster 1: men=38.32; women=43.03; Cluster 2: $m e n=28.27$; women=30.93). STAI-State also showed elevated scores for both genders in Cluster 1 (STAI-State Cluster 1: men=40.44; women=43.00; Cluster 2: men=28.27; women=30.87). BDI results also suggested that members of the Cluster 1 experienced inferior conditions compared to the Cluster 2 group (BDI scores, Cluster 1: men=5.97; women=7.94; Cluster 2: men=0.90; women=2.03).

\section{Coping mechanism}

When we investigate an individual's or couple's psychological reaction for distress, we have to consider the person's coping strategies, that are fundamentally determine their 
reactions. Every cognitive or behavioral effort that tries to cope with an internal or external distress factor can be called a coping mechanism [36]. In the literature there are numerous methods and instruments for examining and classify coping strategies. The common in these classifications, that they determine two main dimensions of coping mechanisms: (i) the problem-solving and (ii) the emotion-focused strategies [37].

The problem-solving coping mechanisms actively change or eliminate the circumstances that directly trigger stress, while emotion-centered coping mechanisms control the emotions provoked by the stressful life situations. If we perceive the environment as changeable, we use problem-solving strategies, if we define it unchangeable, we prefer emotion-centered approach [36]. For most men and women, infertility is a life-changing experience that often carries unexpected stressors and potential stigmatization [38]. Over the past few decades, many authors have connected involuntary childlessness, as a hardly adaptable condition with the coping mechanisms [21].

Peterson et al. found typical gender-specific coping strategies their study among infertile couples [38]. Men's typical coping mechanism was distancing and self-control, while women preferred seeking professional support, seeking social support, and taking responsibility. An American meta-analysis found similar results [39]. Among infertile couples, wives used more frequently emotional-focused coping strategies. Women used the strategies of Seeking Social Support, Escape and Avoidance, Planful Problem-Solving, and Positive Reappraisal to a greater degree than their partners. In a British study's the authors aimed to define which behavioral characteristics are responsible for the different distress-reactions between genders. As method they chose to size up coping mechanisms among men diagnosed with infertility in their infertility clinic. They found that subjects with depression and anxiety symptoms frequently used escape-avoiding coping strategies, they were inclined to stress more and rarely searched or accepted social support than their women partners [40].

In our second study we observed attitudes toward alcohol usage amongst infertile couples. Based on our results, $6,3 \%$ of women and $15.6 \%$ of men were facing serious alcohol problems. Our results are in the line with the literature. A finish study aimed to examine mental disorders, depression, psychological distress, perceived health and quality of life among women and men who have experienced infertility [25]. According to their results, $17 \%$ of childless men and $7 \%$ of childless women had alcohol problems (while amongst men with a child it was only $11 \%$, and women with a child only $1 \%$ ). They concluded the necessity of gender-specific psycho-social support and follow-up for infertile people. In addition, we found that amongst 
infertile couples with worst mental status in Cluster 1 there was a higher risk for alcohol dependency. Using drugs or drinking alcohol is a typical form of escape-avoiding coping strategy, what is obviously a maladaptive mechanism, and as we saw earlier, usually used by men.

Taking these gender-specific coping strategies into account, it is possible that the psychological involvement of infertile men is under-measured in the literature. In addition having wrong spousal communication and using maladaptive strategies (e.g. the avoiding coping strategy) eventuate significantly higher infertility-specific distress in both genders [41]. For an infertile couple, it would be essential to learn an adaptive coping strategy to reduce distress. Adequate coping mechanisms should be considered for psychotherapeutic treatment of infertility.

\section{Dyadic approach}

Although it is obvious that the unintended childlessness has huge psychological burden on both members of the affected couple, decisive proportion of the literature focus on the gender differences of mental health. Nonetheless the unfulfilled desire is a common burden, the affected couple has to face together with this serious difficulty. Realizing this, the trend of the last year's studies is to examine the infertile couples as mentally interacting persons, not only as individuals [22].

Therefore, the aim of our second study was to examine infertile couples and how they affect to each other's psychological state. We investigated symptoms of depression, anxiety, state of well-being and general health by several instruments (BDI, STAI, SCL-90-R, WHO-5WBI, AUDIT, FTND) in our study. A model free clustering approach was used, and the interdependence of spouses was analyzed regarding the infertility related psychological burden. In the line with the literature the trend was observed that women experienced higher levels of perceived stress and depression in general, compared to men. The results revealed that infertile couples could be separated based on the scores of SCL-90-R, STAI-State - Trait and the BDI. Using these instruments, we were able to identify two, significantly different clusters. One (Cluster 1) with relatively high and a second (Cluster 2) group with relatively low scores. Cluster 1 could be typified as one in which spouses experienced more expressed infertility related psychological symptoms, in contrast, couples in Cluster 2 presented lower level of anxiety and depression. Male and female psychological conditions were similar within the clusters, supporting the strong interdependence between the spouses. 
In terms of the dyadic approach our results are in line with the literature as well. An Italian study evaluated the prevalence and the incidence of depressive and anxious symptoms among 1000 couples undergoing assisted reproductive treatment [42]. In the line with the literature 14,7 percent of women showed anxiety, 17,9 percent depression symptoms. Among men this rate was 4,5 and 6,9 percent. Furthermore, the study found additional correlations: women with anxiety or depression symptoms had more frequently anxious partners. Depressed and anxious men had also often spouses with affected mental status. A Korean study's aim was to examine the level of infertility stress, marital adjustment, depression, and quality of life in infertile couples [43]. They found significant actor-partner effects, as the wife's infertility-related stress had a negative impact on the husband's quality of life.

In addition, we found the predictive efficiency of WHO-5-WBI on the likelihood that the infertile couples would be classified into the earlier mentioned Cluster 1 or Cluster 2. The results of this one inventory was able to distinguish between infertile couple who were separated into clusters based on their results of BDI, STAI, SCL-90R. It might be used as a first line screening by general practitioners or IVF nurses, and couples with low scores can be referred to professionals for further psychological care. In a recent review, Topp and colleagues pointed out that the WHO-5-WBI is a promising tool for assessing psychological parameters of patients, including depression and anxiety [44]. According to their results the scale has adequate validity both as a screening tool for depression and as an outcome measure in clinical trials and has been applied successfully across a wide range of study fields. In another study Henkel at al. was searching for some suitable method for identify depression in primary care [45]. They found that the WHO-5-WBI, produced significantly greater sensitivity and a better negative predictive value than the other questionnaires. The World Health Organization's recommendation that every patient in primary care should participate in a screening process with the completion of WHO-5-WBI as a standard first step, done in the waiting room [46].

In our study we found that higher level of the WHO-5-WBI predicts lower scores on the scales of BDI, STAI, SCL-90-R. This result and our ROC analysis supported that WHO-5-WBI questionnaire may be a useful tool in short mental-health assessment. It had a good separative ability on general mental health. Therefore, the WHO-5-WBI was suitable for determining the two clusters and identified couples with elevated level of psychological burden with good accuracy. In case a couple is screened using WHO-5-WBI, an expert could decide further diagnostic or therapeutic steps, and with this method, an increased diagnostic efficiency and more targeted care can be achieved. 


\section{Supportive psychotherapy}

Although in Hungary the somatic care of infertility keeps up with other developed countries' protocols, the mental support of unintended childlessness is still just evolving [47]. As earlier discussed, serious mental burdens due infertility affect not only the general wellbeing but the reproductive functions and also the IVF outcomes, thus the change of this attitude would be crucial [20]. In line with the literature, both of our studies proved the negative psychological effect of infertility on men and women.

In the past decades a large body of literature emphasized the need of psychological services within routine fertility care [48]. Such perspectives mandate the need for mental health as an onsite professional in infertility clinics and highlights on the need to tackle three sources of treatment discontinuation, namely patient-related, clinic-related and treatment-related outcomes. Patient-related outcome can be low emotional tolerance or psychological vulnerability. Clinic-related outcome for example the technology or environment, treatmentrelated outcome can be disruption of social life or work life. An infertility-related counseling has to be different from a usual 'disease consultation', focusing on the emotional crisis of the unfulfilled wish, the frustration because of the long-lasting wait or the anxiety of the repeated treatments [48]. Psychological interventions that are most frequently used for decrease psychological burden in infertile men and women are cognitive-behavioral therapy and BodyMind Intervention [49].

Cognitive behavioral therapy is a short-term therapy technique with limited sessions that can help people find new ways to behave by changing their thought patterns [50]. As a part of a cognitive behavioral therapy can be learning correct thinking techniques, recognizing negative thoughts or attitudes that can negatively effect on mental health, relaxing breathing techniques or simply education about the anatomy of the reproductive system. We recognized in both of our studies that education about the connection between lifestyle and reproductive health would be important, since a huge proportion of the examined patients showed smoking or drinking attitude regularly.

In an American research Domar and his colleagues' s aim was to determine the efficacy of cognitive-behavioral group therapy on viable pregnancy rates in women experiencing infertility less than two years duration [51]. Participants met for two hours per week for ten weeks and used various a cognitive-behavioral technique, such as relaxation-response training, cognitive restructuring or emotional expression. According to their results women who 
participated in a group psychological intervention had significantly increased viable pregnancy rates compared to women who did not participate in any psychological intervention. Another research aimed to determine factors affecting depression in infertile couples and to measure the impact of a psychological intervention before or during infertility treatment [52]. Their results showed the usefulness of psychological intervention among infertile couples in terms of depression. The mean and standard deviation of Beck scores were in a range of $18.7 \pm 9.7$ to $10.7 \pm 5.8$ in the group that was psychologically treated before they received infertility treatment. In our opinion, based on the earlier discussed gender-specific and also maladaptive coping mechanisms, it could be the part of a cognitive-behavioral therapy to learn the adequate coping strategies.

The other frequently used psychological intervention form is the Body-Mind Intervention or mindfulness psychotherapy. The Body-Mind psychotherapy intervention is intended to develop willingness/acceptance through a process of contacting the present moment and being in touch with the unfolding experience in an open and nonjudgmental way [53]. In a recent research Galhardo and his colleagues's aim was to present and determine the impact of the Mindfulness-Based Program among infertile women [53]. For their study they enrolled fifty-five infertile women to complete the program and thirty-seven as a control group. The therapy implied group sessions held in every $10^{\text {th }}$ week in duration around 2 hours of each. By the end of the process, women who attended the program revealed a significant decrease in depressive symptoms, internal and external shame, entrapment, and defeat. Women in the control group did not present significant changes in any of the psychological measures, except for a decrease in self-judgment. In another study Kalhori et al. wanted to evaluate the effect of mindfulness-based group counseling on depression symptoms using BDI in infertile women undergoing IVF [54]. Their research included 90 infertile women separated to an intervention and a control group. The intervention group had eight 90-minutes-long sessions for four weeks. They found that the depressive symptom score among women in the intervention group decreased significantly after the intervention. In contrast, the depressive symptom score in control women was higher after the intervention than before.

As we can observe, the literature confirms not only the necessity but the effectivity of the psychological help. Nevertheless, the worst difficulty of the healthcare institutions is usually the lack of financial, material and professional stuff background. Our second study's results could offer solution to this problem hence only the 53.1 percent of the enrolled patients were divided to Cluster 1, which included people with high psychological burden. Thus, only around 
half of the examined patients would need mental support according to our results. Also, the huge part of the earlier cited literature found only a part of the examined infertile patients psychologically affected. An effective method for measure the mental status of the couples who attend in infertility clinic would be undeniably required. For this purpose, in our second study we applied the instrument WHO-5-WBI to the infertile couples, due it is a short, simple test appropriate to distinguish between the clusters with high mental burden and those couples/spouses who probably do not need psychological help. The reliability of WHO-5-WBI of separating infertile couples based on their psychological state was based on multiple instruments (BDI, STAI-S, STAI-T, SCL-90-R) used in our second study. The main argument for using the WHO-5-WBI is that it contains only 5 items and can be applied quickly during the exploration phase [55]. To underline the importance of using shorter methods we can compare our two studies results. In our first study, where we used a shorter pack of instruments, the percentage of participating was $96 \%$. On the other hand, in our second study with a broader instrument package, the same ratio was only 61\%. The World Health Organization's recommendation that every patient in primary care should participate in a screening process with the completion of WHO-5-WBI based on that, that the World Health Organization set up a short and effective instrument to measure the psychological status of any patient [46]. During the logistic regression analysis, WHO-5-WBI scores, as independent variable, changed contrary to the values of the cluster variables. The higher level of the WHO-5-WBI predicts lower scores on the scales of BDI, STAI, SCL-90-R. This result and ROC analysis support that WHO-5WBI questionnaire may be a useful tool in short mental-health assessment, and it has a good ability to separate regarding general mental health. In our study sample, the WHO-5-WBI was suitable for determining the two clusters and identified couples with elevated level of psychological burden with good accuracy. After a couple filled the WHO-5-WBI, an infertility expert is able to decide further diagnostic or therapeutic steps, and with this method, an increased diagnostic efficiency and more targeted care can be achieved.

It has to be decided in further researches, whether the WHO-5-WBI questionnaire can have a role in the follow-up process and it is suitable for monitoring the improvement in the psychological state of the counseled couples. Furthermore, it is also a subject of interest, what is the optimal follow-up frequency of the psychological screening, because the mental condition of the couples can worsen during the prolonged fertility treatment, or in case of failed IVF cycles [56]. We can assume, also based on our first study that both the depression and anxiety symptoms increase due to the distress of diagnosis or the treatments. 


\section{Limitations}

Undoubtedly, our study has some limitations. In the developed countries only 56,1 percent of the infertile couples search medical help, in some of the countries this proportion is under 45 percent [15]. In the developing countries the average is 51,2 percent, some countries it does not reach 30 percent. Thus, it is hard to estimate the psychological status of this hidden part of infertile population and to create a representative summary of the mental burden of unintended childlessness. In Hungary the average may be larger due to our health care system, where the access to the infertility specialist is good, even if it is an andrology or a gynecology expert. In our first study the examined men's psychological status possibly influenced by their partners', but in our second study we have corrected this limitation.

Furthermore, only $61 \%$ of invited couples took part in the second research, which may affect our conclusion. It is possible, that couples in the worst psychological conditions did not fill the questionnaires. Hopefully, using only a short test as the WHO-5-WBI may increase the willingness of couples to participate in the psychological screening. Another limitation of our study is that we have not included questionnaires examining the coping strategies of the spouses, which can be the topic of a further study. 


\section{Conclusion}

In our first study unexpectedly, low levels of depressive and anxiety symptoms were found in men at the start of infertility evaluation. A significant correlation was demonstrated between the duration of infertility and the level of depressive symptoms. In contrast there was no correlation between the duration of infertility and the level of anxiety. Based on these results and the known literature, the symptoms of anxiety and the higher depression level seems to relate to the infertility treatment itself. No correlation was found between sperm characteristics and the levels of depressive or anxiety symptoms in this study. In our first research we did not pay attention to the spousal effect that we did in our second study. As we know, it was the first research, which was able to classify couples into two significantly different clusters regarding the infertility-related psychological burden. The mental conditions of the spouses were interdependent and similar; they were assigned into the same cluster allowing us to handle them as a dyad. However, scores from BDI, STAI, and SCL-90R questionnaires characterized mostly the mental health of the couples. But the WHO-5-WBI questionnaire also was able to identify couples with significant psychological burden. These patients need professional mental support during the infertility treatment, and we believe, based on our results, that WHO-5-WBI is a convenient tool for health care providers and the patients to identify the couples at need. The part of a psychological intervention could be the education about the link between lifestyle and infertility and also to learn the adaptive coping strategies to deal with this distressful part of the infertile couple's life. 


\section{References}

1. Kirkpatrich, C., The family. The Ronald Press Company, 1963: p. 507-512.

2. Tóth, O., Új anyák és új apák. A gyermekvállalás motivációi. Demográfia, 2012. 55. évf. 2-3. szám: p. 136.-146.

3. Stobel-Richter, Y., et al., The 'wish to have a child', childlessness and infertility in Germany. Hum Reprod, 2005. 20(10): p. 2850-7.

4. Dyer, S., et al., Motives for parenthood among couples attending a level 3 infertility clinic in the public health sector in South Africa. Hum Reprod, 2008. 23(2): p. 352-7.

5. Fisher, J.R. and K. Hammarberg, Psychological and social aspects of infertility in men: an overview of the evidence and implications for psychologically informed clinical care and future research. Asian J Androl, 2012. 14(1): p. 121-9.

6. Fisher, J.R., G.H. Baker, and K. Hammarberg, Long-term health, well-being, life satisfaction, and attitudes toward parenthood in men diagnosed as infertile: challenges to gender stereotypes and implications for practice. Fertil Steril, 2010. 94(2): p. 57480.

7. van Balen, F. and T.C. Trimbos-Kemper, Involuntarily childless couples: their desire to have children and their motives. J Psychosom Obstet Gynaecol, 1995. 16(3): p. 13744.

8. Boivin, J., et al., International estimates of infertility prevalence and treatment-seeking: potential need and demand for infertility medical care. Hum Reprod, 2007. 22(6): p. 1506-12.

9. Nations., U. World Population Prospects 2019. 2019; Available from: https://population.un.org/wpp/Graphs/DemographicProfiles/Line/900.

10. OECD. Fertility rates. 2020; Available from: https://data.oecd.org/pop/fertilityrates.htm.

11. Nations., U. World fertility patterns 2015. 2015; Available from: https://http://www.un.org/en/development/desa/population/theme/fertility/index.asp.

12. KSH. Népesség, népmozgalom 1900-. 2020; Available from: https://http://www.ksh.hu/docs/hun/xstadat/xstadat eves/i wnt001b.html.

13. McDevitt, T.M., World population profile 1998. U.S. Government Printing Office, 1999: p. A39-40.

14. Gillian R. Bentley, C.G.N.M.-T., Infertility in the modern world: Present and Future Prospects. Biosocial Society Symposium Series ,Cambridge University Press, 2000. 12: p. 45.

15. Miettinen A, S.I., Childlessness intentions and ideals in Europe. Finnish Yearbook of Population Research, 2014. 49: p. 31-55.

16. Commission., E., Eurobarometer 75.4 (2011). TNS OPINION \& SOCIAL, Brussels [Producer]. in GESIS Data Archive, Cologne. ZA5564 Data fi le Version 3.0.1. 2014.

17. Takács, I.S.J., Who Remains Childless? Unrealised Fertility Plans in Hungary. Czech sociological review 51(6):1047, 2015.

18. Vander Borght, M. and C. Wyns, Fertility and infertility: Definition and epidemiology. Clin Biochem, 2018. 62: p. 2-10.

19. Freeman, E.W., et al., Psychological evaluation and support in a program of in vitro fertilization and embryo transfer. Fertil Steril, 1985. 43(1): p. 48-53.

20. Younglai, E.V., A.C. Holloway, and W.G. Foster, Environmental and occupational factors affecting fertility and IVF success. Hum Reprod Update, 2005. 11(1): p. 43-57. 
21. Norbert Pásztor, B.E.H., Edina Dombi, Gábor Németh, Psychological Distress and Coping Mechanisms in Infertile Couples. The Open Psychology Journal, 2019. 12: p. 169-173.

22. Cserepes, R.E., T. Korosi, and A. Bugan, [Characteristics of infertility-specific quality of life in Hungarian couples]. Orv Hetil, 2014. 155(20): p. 783-8.

23. Volgsten, H., et al., Prevalence of psychiatric disorders in infertile women and men undergoing in vitro fertilization treatment. Hum Reprod, 2008. 23(9): p. 2056-63.

24. Drosdzol, A. and V. Skrzypulec, Depression and anxiety among Polish infertile couples--an evaluative prevalence study. J Psychosom Obstet Gynaecol, 2009. 30(1): p. 11-20.

25. Klemetti, R., et al., Infertility, mental disorders and well-being--a nationwide survey. Acta Obstet Gynecol Scand, 2010. 89(5): p. 677-82.

26. Rossi, V. and G. Pourtois, Transient state-dependent fluctuations in anxiety measured using STAI, POMS, PANAS or VAS: a comparative review. Anxiety Stress Coping, 2012. 25(6): p. 603-45.

27. Edelmann, R.J., M. Humphrey, and D.J. Owens, The meaning of parenthood and couples' reactions to male infertility. Br J Med Psychol, 1994. 67 ( Pt 3): p. 291-9.

28. Wichman, C.L., et al., Comparison of multiple psychological distress measures between men and women preparing for in vitro fertilization. Fertil Steril, 2011. 95(2): p. 717-21.

29. Peterson, B.D., et al., Are severe depressive symptoms associated with infertility-related distress in individuals and their partners? Hum Reprod, 2014. 29(1): p. 76-82.

30. Volgsten, H., et al., Risk factors for psychiatric disorders in infertile women and men undergoing in vitro fertilization treatment. Fertil Steril, 2010. 93(4): p. 1088-96.

31. Khademi, A., et al., Pretreatment Beck Depression Inventory score is an important predictor for post-treatment score in infertile patients: a before-after study. BMC Psychiatry, 2005. 5: p. 25.

32. Reis, S., et al., Psychological impact of single and multiple courses of assisted reproductive treatments in couples: a comparative study. Eur J Obstet Gynecol Reprod Biol, 2013. 171(1): p. 61-6.

33. Ramezanzadeh, F., et al., A survey of relationship between anxiety, depression and duration of infertility. BMC Womens Health, 2004. 4(1): p. 9.

34. Ahmadi, H., et al., Male infertility and depression: a neglected problem in the Middle East. J Sex Med, 2011. 8(3): p. 824-30.

35. Zorn, B., et al., Psychological factors in male partners of infertile couples: relationship with semen quality and early miscarriage. Int J Androl, 2008. 31(6): p. 557-64.

36. Lazarus, R.S., Coping theory and research: past, present, and future. Psychosom Med, 1993. 55(3): p. 234-47.

37. Pléh, O.B.C., Bevezetés a pszichológiába. 2006: Osiris Kiadó Kft. 451-470.

38. Peterson, B.D., et al., Gender differences in how men and women who are referred for IVF cope with infertility stress. Hum Reprod, 2006. 21(9): p. 2443-9.

39. Jordan, C. and T.A. Revenson, Gender differences in coping with infertility: a metaanalysis. J Behav Med, 1999. 22(4): p. 341-58.

40. al., D.A.B.e., Correlates of psychological distress in relation to male infertility. British Journal of Health Psychology, 2011.

41. Schmidt, L., et al., Communication and coping as predictors of fertility problem stress: cohort study of 816 participants who did not achieve a delivery after 12 months of fertility treatment. Hum Reprod, 2005. 20(11): p. 3248-56.

42. Chiaffarino, F., et al., Prevalence and incidence of depressive and anxious symptoms in couples undergoing assisted reproductive treatment in an Italian infertility department. Eur J Obstet Gynecol Reprod Biol, 2011. 158(2): p. 235-41. 
43. Kim, J.H., H.S. Shin, and E.K. Yun, A Dyadic Approach to Infertility Stress, Marital Adjustment, and Depression on Quality of Life in Infertile Couples. J Holist Nurs, 2018. 36(1): p. 6-14.

44. Topp, C.W., et al., The WHO-5 Well-Being Index: a systematic review of the literature. Psychother Psychosom, 2015. 84(3): p. 167-76.

45. Henkel, V., et al., Identifying depression in primary care: a comparison of different methods in a prospective cohort study. BMJ, 2003. 326(7382): p. 200-1.

46. WHO, Wellbeing measures in primary health care/ the depcare project - report on a WHO meeting. 1998.

47. Lörincz, J.S.B.K.J., Psychological concerns of female reproductive health. Orvosképzés, 2014.

48. Patel, A., P. Sharma, and P. Kumar, Role of Mental Health Practitioner in Infertility Clinics: A Review on Past, Present and Future Directions. J Hum Reprod Sci, 2018. 11(3): p. 219-228.

49. Masoumi, S.Z., et al., What Psychiatric Interventions Are Used for Anxiety Disorders in Infertile Couples? A Systematic Review Study. Iran J Psychiatry, 2019. 14(2): p. 160170.

50. Davis, K. How does cognitive behavioral therapy work? 2018; Available from: https://http://www.medicalnewstoday.com/articles/296579.

51. Domar, A.D., et al., Impact of group psychological interventions on pregnancy rates in infertile women. Fertil Steril, 2000. 73(4): p. 805-11.

52. Noorbala, A.A., et al., Effects of a psychological intervention on depression in infertile couples. Int J Gynaecol Obstet, 2008. 101(3): p. 248-52.

53. Galhardo, A., M. Cunha, and J. Pinto-Gouveia, Mindfulness-Based Program for Infertility: efficacy study. Fertil Steril, 2013. 100(4): p. 1059-67.

54. Kalhori, F., et al., Effect of Mindfulness-Based Group Counseling on Depression in Infertile Women: Randomized Clinical Trial Study. Int J Fertil Steril, 2020. 14(1): p. 1016.

55. Heun, R., et al., Internal and external validity of the WHO Well-Being Scale in the elderly general population. Acta Psychiatr Scand, 1999. 99(3): p. 171-8.

56. Newton, C.R., M.T. Hearn, and A.A. Yuzpe, Psychological assessment and follow-up after in vitro fertilization: assessing the impact of failure. Fertil Steril, 1990. 54(5): p. 879-86. 